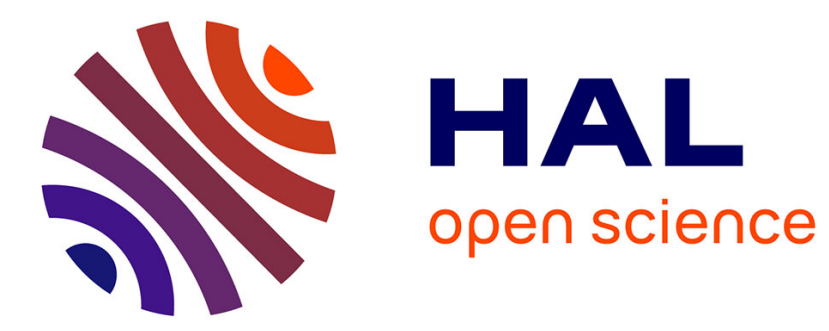

\title{
Multi-homing and Software Firm Performance
}

Sami Hyrynsalmi, Matti Mäntymäki, Aaron W. Baur

\section{To cite this version:}

Sami Hyrynsalmi, Matti Mäntymäki, Aaron W. Baur. Multi-homing and Software Firm Performance. 16th Conference on e-Business, e-Services and e-Society (I3E), Nov 2017, Delhi, India. pp.442-452, 10.1007/978-3-319-68557-1_39. hal-01768493

\section{HAL Id: hal-01768493 \\ https://hal.inria.fr/hal-01768493}

Submitted on 17 Apr 2018

HAL is a multi-disciplinary open access archive for the deposit and dissemination of scientific research documents, whether they are published or not. The documents may come from teaching and research institutions in France or abroad, or from public or private research centers.
L'archive ouverte pluridisciplinaire HAL, est destinée au dépôt et à la diffusion de documents scientifiques de niveau recherche, publiés ou non, émanant des établissements d'enseignement et de recherche français ou étrangers, des laboratoires publics ou privés. 


\title{
Multi-homing and Software Firm Performance: Towards a Research Agenda
}

\author{
Sami Hyrynsalmi1 ${ }^{\text {[0000-0002-5073-3750] }}$, Matti Mäntymäki ${ }^{2}$ [0000-0002-1981-566X] \\ and Aaron W. Baur ${ }^{3}$ \\ ${ }^{1}$ Tampere University of Technology, Pori, Finland \\ sami.hyrynsalmietut.fi \\ ${ }^{2}$ Turku School of Economics, University of Turku, Finland \\ matti.mantymaki@utu.fi \\ ${ }^{3}$ ESCP Europe Business School Berlin, Berlin, Germany \\ abaurdescpeurope.eu
}

\begin{abstract}
Joining or leaving a platform ecosystem is a key strategic decision for software developers. 'Multi-homing' is a strategy in which a company distributes its products via more than one platform ecosystem in parallel. 'Single-homing' is an opposite strategy. On one hand, multi-homing can increase customer reach in markets where customers typically single-home. On the other hand, creating a new version of the software product for multi-homing purposes generates, e.g., conversion, maintenance, and marketing cost. Interestingly, multi-homing as a strategic choice in software business has thus far have received surprisingly little academic scrutiny. In particular, there is very little information on whether multihoming is an economically viable distribution strategy. To fill in this void, we explore the financial performance between single-homers and multi-homers in mobile application ecosystems. In this paper, we investigate how the decision to multi-home affects firm performance with a sample of mobile application developers. The results imply that the revenue growth has been faster among singlehomers while our dataset is biased towards single-homers. This calls for additional research comparing the two distribution strategies. This paper acts as a starting point for a research agenda in order to better understand multi-homing as a strategic choice in software business.
\end{abstract}

Keywords: Multi-homing, Platforms, Software ecosystems, Strategic management, Two-sided markets.

\section{Introduction}

Ecosystems and platforms are today regarded as important elements of doing business [16]. Since terminology in this field has not yet stabilized and some terms are used interchangeably [c.f. 11, 23], we follow the view that a technological platform is a core of an ecosystem that enables its formation [5]. An ecosystem itself consists of a platform and its owner, complements and their providers, as well as customers [8]. Well-known 
examples of such ecosystems include marketplace-centred mobile application ecosystems (e.g., Apple's App Store for iOS devices and Google Play for Android operating system devices).

As ecosystems and platforms have become a major distribution challenge in software business [14], the decision to single-home or multi-home is a key strategic issue for many software companies. In economic theory, multi-homing refers to participating in more than one competing marketplace in parallel [20]. In today's software development and software business, multi-homing typically means distributing a product via more than one competing platform such as Android and iOS at the same time whereas singlehoming refers to distribution the software product via only one platform [4].

Since ecosystems typically have entry barriers [19], a multi-homing strategy incurs costs to the software developer. In software ecosystems, typical entry barriers are fees for participation, ecosystem-specific development tools that are not interchangeable or the need for specific programming skills. For example, Google Play features a 25 USD registration fee and the official development tool is Android Software Development Kit (SDK). For App Store, a membership is 99 USD and the official tool is iOS SDK. The Android SDK and iOS SDK and are not cross-compatible.

While nowadays there are tools that reduce the costs of cross-platform software development, such as Apache Cordova or Titanium [1, 6], multi-homing always generates some additional costs related to e.g. development, maintenance, product management, and marketing of a new platform-specific version. Thus, the decision to multi-home a firm's contributions to more than one ecosystem requires careful balancing between the potential for gaining a larger market share [21] or reducing dependency on a single ecosystem orchestrator [15] on the one hand and the increased costs [7] on the other hand.

Against this backdrop, it is surprising that the effects of adopting a multi-homing vs. single-homing strategy in terms of software developer's financial performance remains largely opaque in software business literature [8]. Most of the extant literature on multihoming focuses on the ecosystem level analysis while firm-level investigations of multi-homing as a strategic distribution choice and its outcomes on firm performance remain largely absent. However, the decision between multi-homing and single-homing strategy represents a key strategic decision for a large number of software firms.

Therefore, the purpose of this study is to shed light on a fundamental question for many software developers: Does it pay off to multi-home?

To this end, we obtained a set of data consisting of 10,000 mobile application developers that distribute their products via Apple's App Store, Google Play, and Microsoft's Windows Phone Store. We then investigated their product offerings to identify the companies that multi-home and acquired their financial information from the ORBIS database. Finally, we compare the turnover growth of 812 mobile application vendors to detect if multi-homing pays off or not.

The remainder of the paper is structured as follows. In the second section, we present an overview of prior research on multi-homing in software business. In Section 3, we describe the research approach and data collection, followed by the results in the fourth section. In Section 5, we discuss the findings, unveil the limitations and put forward suggestion for future research. 


\section{Multi-homing in software platforms}

Multi-homing can have a profound effect on platform competition dynamics and thus ultimately the very structure of the entire market $[5,7,9,22,24]$. With respect to software platforms, in presence of several competing platforms the structure of the market depends on multi-homing patterns of application developers [22]. According to Sun and Tse [22], extensive multi-homing among application developers enables competition between platforms whereas single-homing eventually turns the market towards a single dominant ecosystem.

Landsman and Stremersch [18] in turn studied multi-homing in the gaming console market. Their results demonstrate that initially a multi-homing strategy hurts the sales of the hardware consoles but this effect fades away when the ecosystem ages. Landsman and Stremersch [18] further divided multi-homing into two different categories: 1) Seller-level multi-homing that refers to a situation where the same producer, e.g. an application developer works for several ecosystems. 2) Platform-level multi-homing refers to a situation where a developer, or someone else, distributes the same product via several ecosystems.

While the two forms of multi-homing are likely to be correlated, it is also possible that a developer offers different product for different ecosystems - or different developers offer a certain product to different developers to different ecosystems. As an example of the latter, the Facebook apps in Google Play and Apple Store were developed by Facebook whereas the Facebook app in Windows Store was developed and published by Microsoft a few year ago.

According to Hyrynsalmi et al. [10], the overall number of multi-homing is small in mobile application markets. However, the most popular applications are available in all competing ecosystems and the producers of these applications largely multi-home [14]. Hyrynsalmi et al. [14] describe this situation as a multi-level two-sided market to underscore the difference between the level of multi-homing in general and multi-homing among the most popular applications.

Despite the theoretical and conceptual contributions in the field, empirical studies focusing on software developers' multi-homing behaviour remain scant. Idu, van de Zande, and Jansen [15] analysed multi-homing inside Apple's three different sub-ecosystems. They found $17.2 \%$ platform-level multi-homing in their set of 1,800 mobile applications. In their empirical analysis of multi-homing in the three leading (Android, iOS, and Windows Phone) mobile application ecosystems, Hyrynsalmi, Suominen and Mäntymäki [14] found that only 1.7-3.2\% of all applications (i.e. platform-level) and 5.8-7.2\% all developers (i.e., seller-level) in the three mobile application operating systems were multi-homing. Interestingly, however, from the most popular applications $41-58 \%$ were multi-homing. Similarly, 42-69\% of the keystone developers, i.e. producers of the most popular applications, were multi-homing.

Burkard, Widjaja and Buxmann [3] in turn studied popularity of multi-homing strategy in SaaS business solutions market. Interestingly, they found only 70 multi-homers (ca. $3.5 \%$ ) from their dataset of over two thousand software vendors.

Nevertheless, the surveys on the popularity of the multi-homing approach show that often times only a small fraction has adopted a multi-homing as a distribution strategy. 
However, it seems that number of adopters are rising. For example, when the results of Hyrynsalmi et al. [14] and Idu et al. [15] are compared to Boudreau's study a decade earlier in the mobile application market [2], exhibiting an overall multi-homing rate of less than 1 per cent, a clear growth in the number of multi-homing strategy adopters can be seen. This might be a result of either the growth of mobile application market's value [c.f. 8], the development of technological tools for multi-homing [c.f. 1], or because of a wider understanding of the platform economy and its rules [c.f. 16].

Altogether, the number of studies specifically focusing on the impact of multi-homing to particular software companies is very low. To the best of the authors' knowledge, only one prior study has examined this topic. With a cross-segment approach, Hyrynsalmi, Suominen, Jansen and Yrjönkoski [12] analysed multi-homing of Finnish computer game companies. In their study, they included all game companies ranging from mobile game and social media add-ons to AAA class video game developers. Out of the 208 active game companies, they found that a majority (54.8\%) were multihomers. However, they did not find any major differences between multi-homers' and single-homers' financial performances.

To summarize, a clear majority of existing work focuses on a market-level analysis and on the impacts of multi-homing to a market as a whole [e.g. 5, 18, 22]. However, there is a dearth of studies addressing how multi-homing affects individual companies. While there are arguments for and against the use of a multi-homing publishing strategy $[7,14,15]$ and the importance of multi-homing to the development of the whole market $[5,7,22]$, it is surprising that there is little empirical evidence evaluating the (potential) economic benefit for a single developer to multi-home.

To fill in this void, in the literature, the present study aims to explore whether there is evidence that multi-homing is a financially superior choice than single-homing for a software developer. We particularly focus on mobile application ecosystems as the market features several competing ecosystem and a large number of application developers of various size and importance.

\section{Empirical research}

To shed light on the question whether it pays off or not to multi-home, we chose revenue growth as the focal indicator of the financial viability of multi-homing $v s$. singlehoming. As multi-homing increases the number of potential customers, it should lead to increasing revenues compared to single-homing. As an example, Gartner's latest report $^{1}$ states that in the last quarter of $2016,81.7 \%$ of the new smart phones were using Android operating system and $17.9 \%$ were using iOS devices. However, applications offered in Apple's App Store generate higher revenues than the ones available in

\footnotetext{
${ }^{1}$ Gartner Says Worldwide Sales of Smartphones Grew 7 Percent in the Fourth Quarter of 2016. http://www.gartner.com/newsroom/id/3609817 Accessed May $5^{\text {th }}, 2017$.
} 
Google's Play store ${ }^{2,3}$. Thus, for a mobile application developer to gain the largest audience, it should select the Android operating system whereas it is likely that higher revenue is generated in Apple's App Store.

Revenue growth as an indicator does not take into account the increased costs associated to multi-homing. However, as obtaining information about these costs from financial statements is practically impossible, we concluded that revenue growth is an appropriate measure to extrapolate the pay-off of multi-homing.

We utilized a three-step research process illustrated in Fig. 1. In the first step, to gather the starting data, we employed a web crawler that collected a sample of 10,000 mobile application vendors from three mobile application marketplaces, Google Play, Apple's App Store and Windows Phone Store. From each vendor, we collected the name that the vendor used to presents itself in the marketplace and the number of applications the vendor has published in that marketplace. We then manually doublechecked the data and, e.g. in case of slightly different names between the marketplaces, matched the data. The dataset and the multi-homing information was collected in the beginning of 2013.

In the second step, to acquire financial information regarding the vendors, we used the ORBIS financial information database by Bureau van Dijk. The ORBIS database contains financial information on over 200 million companies globally. We uploaded the list of 10,000 software vendor names for the batch search and used the database's matching logic to identify corresponding companies. As the database allows selecting between various levels of matching accuracy, to maximize the quality of our data, we decided to only accepted matches where the matching quality was given the highest rating ('A').

From the 10,000 software vendor names in our query, a match was found for 3,247 $(32.5 \%)$. As the mobile application developers are known to be a rather heterogeneous set ranging from commercial developers with financial interests to hobbyist and non-

\footnotetext{
${ }^{2}$ App Annie 2015 Retrospective. http://go.appannie.com/report-app-annie-2015-retrospective Accessed May 5 $5^{\text {th }}, 2017$.

3 App Annie 2016 Retrospective. http://go.appannie.com/app-annie-2016-retrospective Accessed May $5^{\text {th }}, 2017$.
} 


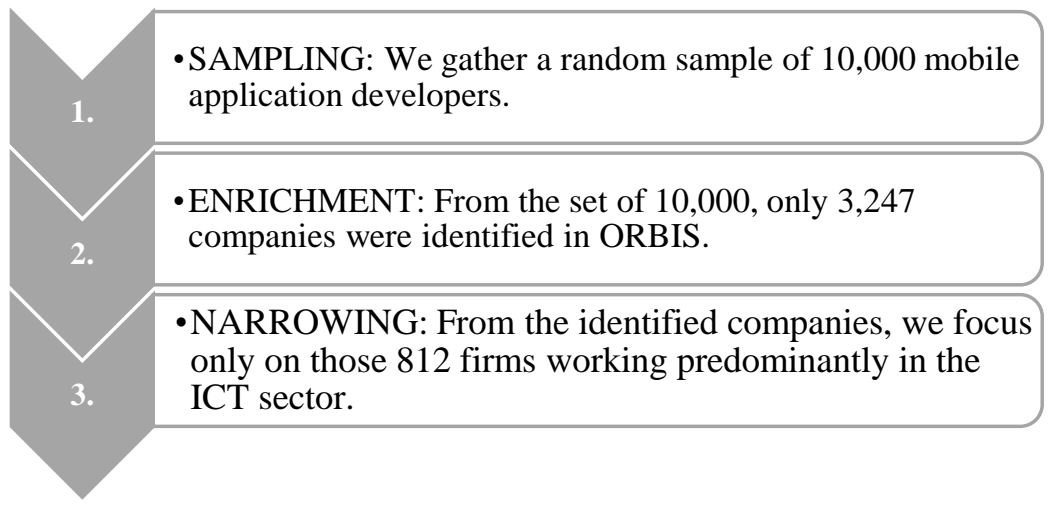

Fig. 1. The process flow of research in this study.

profit organizations [13], it was expected that only a minority of the developers would have founded and registered a company for collecting the income and paying taxes from the applications sales.

Our subscription of ORBIS did not cover financial information of 34 companies, and thus those were excluded from performance analyses. From the identified 3,247 companies, there were companies and organizations from various fields. For example, we found several European airports multi-homing, i.e. providing their apps via all marketplaces.

For all companies, we acquired operating revenue information from the years 2013, 2014 and 2015. Naturally, only for a few companies the financial information of the year 2016 had been reported already; thus, this year is omitted. We use three intervals for measuring the performance growth, i.e. the financial performance is studied through the growth of a company's revenue from the year 2013 to 2014 and 2015 . The reason is that the impact of multi-homing in the revenue of the company might take more than a year. The starting point is 2013 as the multi-homing information of the year 2013 was acquired from the marketplaces.

In the third step of the process, to focus deliberately on companies that are in software business, we added a further constraint to narrow down our results to companies that have defined 'Information and Communication' as their main business domain classification. This query returned a set of 812 companies of which $745(91.7 \%)$ were single-homers and $67(8.3 \%)$ were multi-homers. We thereafter omitted companies with missing revenue information. The final set of ICT companies consisted of 538 companies.

\section{$4 \quad$ Results}

The identified 3,247 companies are from various fields as shown in Fig. 2. The largest sections in our dataset are 'Information and Communication' (808 firms, $30 \%$ of all), 'Wholesale and retail trade' (440, $16 \%)$, and 'Professional, scientific and technical activities' (387, $14 \%$ ). For 200 companies, no information was stored in the data field 


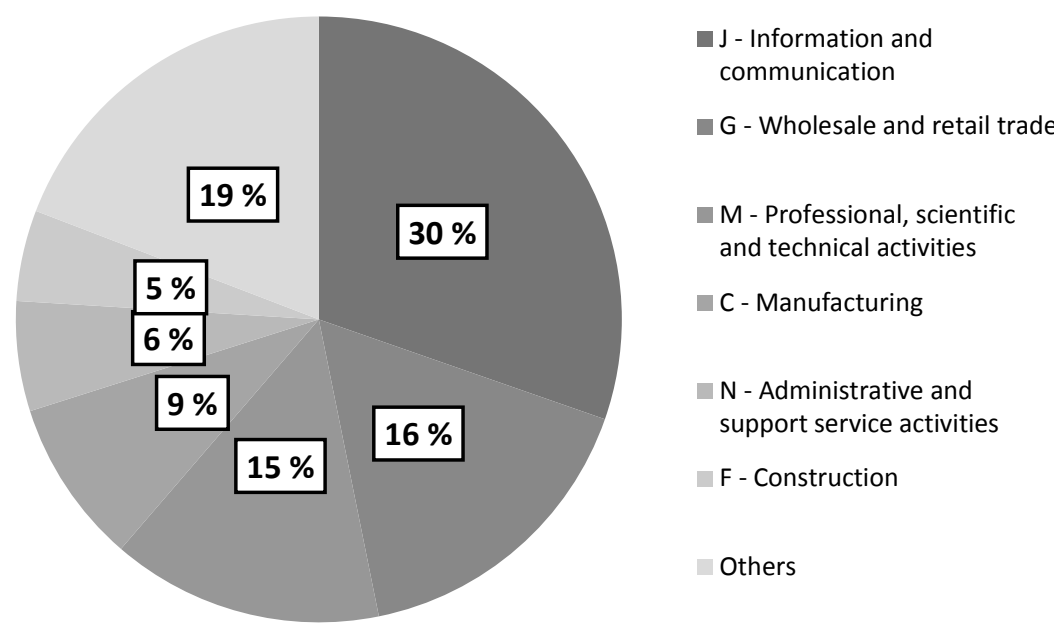

Fig. 2. Distribution of studied companies NACE Rev 2. classifications.

'NACE Rev. 2 main section'. The companies are from 39 different countries while Great Britain, France, Italy and Germany being the biggest country of origin.

The financial indicators are infrequently reported to the database. For example, it is quite common in the dataset that a company might not have any financial indicators stored for a certain year whereas they are available for previous and next years. For example, our full dataset contains financial information of over 3,200 companies. From those, only 1,102 companies have revenue information available for the years 2013 and 2014. Thus, in the forthcoming performance analysis, the number of companies used in each analysis varies.

The average turnover growth for the studied firms are shown in Table 1. When looking at our sample of companies as a whole, the average revenue growth rate from 2013 to 2014 was 80 percent and 2014 to 2015 it was 79 percent. At the same time, the companies in the ICT field grew on average by $54 \%$ and $13 \%$ only.

We identified 209 (6.4\%) companies multi-homing in our set. Out of those, 78 were classified as ICT companies (i.e. belonging to NACE Rev. 2 class ' $\mathrm{J}$ - Information and communication') and 131 into other fields. Thus, $9.6 \%$ of ICT companies are multihoming whereas only $6.2 \%$ of non-ICT companies are multi-homers. While ICT companies are more keen to a multi-home publication strategy than non-ICT companies, the multi-homing rates still remain low.

In the final step of the analysis, we focused on the performance of ICT companies. Hence, we excluded non-ICT companies as there are likely more factors explaining their growth of revenue than solely the decision to publish multi-homed applications. Thus, here we focus on the 812 companies belonging into 'Information and communication' category.

Interestingly, and contrary to our assumptions, the results imply that single-homing ICT companies had stronger growth rates than multi-homers (59\% vs. $14 \%$ in $2013-$ 
Table 1. Average turnover growth and the size of sample

\begin{tabular}{rrrrrrr}
\hline Strategy & $\begin{array}{r}\mathbf{2 0 1 3}- \\
\mathbf{2 0 1 4}\end{array}$ & (n) & $\begin{array}{r}\mathbf{2 0 1 4 -} \\
\mathbf{2 0 1 4}\end{array}$ & (n) & $\begin{array}{l}\mathbf{2 0 1 3}- \\
\mathbf{2 0 1 5}\end{array}$ & (n) \\
\hline All companies & $80 \%$ & $(1,102)$ & $79 \%$ & $(881)$ & $118 \%$ & $(836)$ \\
Single-homing & $86 \%$ & $(1,008)$ & $85 \%$ & $(806)$ & $126 \%$ & $(763)$ \\
Multi-homing & $14 \%$ & $(94)$ & $11 \%$ & $(75)$ & $39 \%$ & $(73)$ \\
$\begin{array}{c}\text { Information and Commu- } \\
\text { nication field }\end{array}$ & $54 \%$ & $(304)$ & $13 \%$ & $(244)$ & $57 \%$ & $(229)$ \\
Single-homing & $59 \%$ & $(271)$ & $14 \%$ & $(218)$ & $51 \%$ & $(205)$ \\
Multi-homing & $14 \%$ & $(33)$ & $1 \%$ & $(26)$ & $26 \%$ & $(24)$ \\
\hline
\end{tabular}

2014, $14 \%$ vs. $1 \%$ in 2014-2015, and $51 \%$ vs. $26 \%$ in 2013-2015) as depicted in Table 1. While the number of multi-homers remains small in each studied set, they are growing considerably slower than the single-homers. A similar phenomenon can be seen also by looking at the average growth of all companies - here again single-homing companies outperform multi-homing companies with a reasonable wide margin.

To summarize, as Table 1 shows, the turnover growth is faster among single-homers than multi-homers during the studied periods. However, the final sample was heavily biased towards single-homers as less than ten percent of the companies are multi-homing. Furthermore, due the sparse availability of financial information, the number of multi-homing ICT-companies remains low. This largely inhibits drawing far-reaching conclusions from the data.

\section{Discussion}

In the following section, we will first discuss the implications of this study. It is followed by a discussion of limitations and some ideas for future work.

\subsection{Implications}

This study was carried out to shed empirical light on a key question in software business, i.e. does it pay off to multi-home? To this end, we conducted an extensive empirical study to identify relevant companies and used the ORBIS financial information database to obtain the relevant financial figures.

While multi-homing is generally considered a desirable strategic choice in software business literature [14], based on the findings from this study, we cannot empirically corroborate, or reject, this notion. While our initial results show that single-homers are performing better in the terms of revenue growth, the number of multi-homing companies with financial information included into the sample remain too low to draw a statistically valid conclusion. 
We started by hypothesizing that multi-homing would incur more costs due to the entry barriers as well as the need of maintaining alternative versions. However, a larger potential buyer population would ultimately provide returns on these investments. Overall, our results support offer at best weak, if any, support for our initial assumption that multi-homing yields into superior financial outcomes than single-homing. However, due to the incomplete financial information and dominance of single-homing companies in our dataset, drawing further conclusions requires require additional empirical evidence.

Even though our ultimate research question remains unanswered, our approach in empirically investigating the issue is nevertheless a definite contribution to software business literature [c.f. 8, 15]. The present study can be seen as a first step towards a research agenda focusing on understanding multi-homing as a strategic choice in software business. To this end, our study demonstrates that relying on publically available financial information as the only source of data is not a sufficient approach to investigate the bottom-line financial effect of multi-homing.

From a practice-oriented perspective, while the effect of multi-homing on turnover development remains unanswered, multi-homing remains a viable strategy to reduce software developers' dependency on a single client platform. Hence, the decision whether to multi-home or not is not solely a matter of maximizing revenue but also essentially about managing risks.

\subsection{Limitations and future research}

Like any other piece of empirical research, our study is subject to a number of limitations. First of all, it is evident that our current data is not sufficient to provide a definite answer to a pivotal research question such as the one posed in this study. Thus, we strictly advice against drawing far-reaching conclusions from the present study. This is because the financial information available from the ORBIS database was incomplete for most companies and concomitantly the number of multi-homers with sufficient financial information reported performance measures was too low to conduct a statistically robust analysis.

As a result, additional research with a new data collection is needed. Furthermore, due to the limitations of the current dataset and the exploratory stance of the study, further studies in the area should control for the potential confounding effects of the various factors that may influence growth rates to meaningfully isolate the influence of multi-homing. Nevertheless, we demonstrated a decent sampling strategy for the selection of mobile application vendors that can be useful for other kinds of studies.

An alternative option would be to change the research stance from quantitative analysis towards a qualitative work. As this study presents, finding statistically relevant results might be problematic (e.g. the selection of performance measures), thus a qualitative case study on multi-homing and single-homing companies could create a better picture of the benefits and drawbacks of a multi-homing publishing strategy.

Finally, in future work, the type of the market or apps should also be reconsidered as they might play a role in the performance analyses. For example, the console gaming market is relatively mature and relationships within the ecosystems often somewhat 
more complex than in the mobile application markets. For example, to mitigate the risks related the high production costs and long development cycles, game developers often sign exclusive deals to publish the game in a single marketplace. Similarly, the development of freemium mobile games features its unique characteristics [see 17]. Thus incorporating a wider selection of different markets and ecosystems would be an advisable course for future research..

\section{Conclusion}

The purpose of the paper was to act as a starting point for a research agenda in order to better understand multi-homing as a strategic choice in software business. The market tendency either towards multi-homing or single-homing has been linked in the extant theories on the future development of the whole market. However, only little has been researched on the impact of multi-homing to companies.

We performed a quantitative study of more than 3,200 companies our empirical data While only a small number of them were found to be multi-homers, it seemed that on average single-homers are performing better than multi-homers. However, due to the small amount of multi-homing companies with sufficient financial information, additional research is needed before drawing further conclusions. As a result, the main contribution of this study resides in address an important question does multi-homing pay off for software companies and introducing an approach to empirically investigate this pivotal question.

\section{References}

1. Ahti, V., Hyrynsalmi, S. and Nevalainen, O. (2016). An evaluation framework for crossplatform mobile app development tools: A case analysis of Adobe PhoneGap framework. In Proceedings of the 17th International Conference on Computer Systems and Technologies 2016. Ed. By B. Rachev, D. Tegolo, Y. Kalmukov, S. Smrikarova, A. Smrikarov. p. 41-48.

2. Boudreau, K. (2007). Too Many Complementors? Evidence on Software Developers. Technical Report hal-00597766, HEC-Paris School of Management. https://hal-hec.archives-ouvertes.fr/hal-00597766

3. Burkard, C., Widjaja, T., and Buxmann, P. (2012). Software ecosystems. Business \& Information Systems Engineering, 4(1):41-44.

4. Caillaud, B. and Jullien, B. (2003). Chicken \& egg: Competition among intermediation service providers. The RAND Journal of Economics 34(2), 309-328.

5. Cusumano, M.A. (2010). Staying Power: Six Enduring Principles for Managing Strategy and Innovation in an Uncertain World (Lessons from Microsoft, Apple, Intel, Google, Toyota and More). Oxford University Press: Oxford, UK.

6. Dhillon, S. and Mahmoud, Q.H. (2015). An evaluation framework for cross-platform mobile application development tools. Software: Practice and Experience 45(10), 1331-1357.

7. Eisenmann, T., Parker, G. and Van Alstyne, M.W. (2006). Strategies for two-sided markets. Harvard Business Review 84(10), 92-101.

8. Hyrynsalmi, S. (2014). Letters from the War of Ecosystems - An Analysis of Independent Software Vendors in Mobile Application Marketplaces. TUCS Dissertations No 188. University of Turku, Turku, Finland (2014). 
9. Hyrynsalmi, S., and Linna, P. (2017) The Role of Applications and their Vendors in Evolution of Software Ecosystems. In: Biljanovic, P. (ed) Proceedings of the 40th International Convention on Information and Communication Technology, Electronics and Microelectronics. IEEE, p. 1686-1691.

10. Hyrynsalmi, S., Mäkilä, T., Järvi, A., Suominen, A., Seppänen, M., and Knuutila, T., (2012a) App Store, Marketplace, Play! An Analysis of Multi-homing in Mobile Software Ecosystems. In Jansen, S., Bosch, J., Alves, C. (eds) Proceedings of the Fourth International Workshops on Software Ecosystems. CEUR Workshop Proceedings 879, CEUR-WS, p. 59-72.

11. Hyrynsalmi, S. Seppänen, M. Nokkala, T., Suominen, A., and Järvi, A. (2015) Wealthy, Healthy and/or Happy - What does 'Ecosystem Health' Stand for? In: Fernandes J., Machado R., Wnuk K. (eds) Software Business. ICSOB 2015. Lecture Notes in Business Information Processing, vol 210. Springer, Cham. p. 272-287.

12. Hyrynsalmi, S., Suominen, A., Jansen, S., and Yrjönkoski, K. (2016a) Multi-homing in Ecosystems and Firm Performance: Does it Improve Software Companies' ROA? In IWSECO 2016 - Proceedings of the International Workshop on Software Ecosystems. CEUR Workshop Proceedings 1808, CEUR-WS. p. 56-69.

13. Hyrynsalmi S., Suominen A., Mäkilä T., Järvi A., and Knuutila T. (2012b) Revenue Models of Application Developers in Android Market Ecosystem. In: Cusumano M.A., Iyer B., Venkatraman N. (eds) Software Business. ICSOB 2012. Lecture Notes in Business Information Processing, vol 114. Springer, Berlin, Heidelberg. p. 209-222.

14. Hyrynsalmi, S., Suominen, A. and Mäntymäki, M. (2016b). The influence of developer multi-homing on competition between software ecosystems. Journal of Systems and Software $111,119-127$.

15. Idu, A., van de Zande, T. and Jansen, S. (2011). Multi-homing in the Apple ecosystem: Why and how developers target multiple Apple App Stores. In Proceedings of the International Conference on Management of Emergent Digital EcoSystems. New York: ACM. p. 122128.

16. Kenney, M. and Zysman, J. (2016). The Rise of the Platform Economy. Issues in Science and Technology 32(3).

17. Koskenvoima, A., and Mäntymäki, M. (2015). Why do small and medium-size freemium game developers use game analytics? In proceedings of the $14^{\text {th }}$ IFIP Conference on e-Business, e-Services, and e-Society (I3E2015). Lecture Notes in Computer Science, 9373.

18. Landsman, V. and Stremersch, S. (2011). Multi-homing in two-sided markets: An empirical inquiry in the video game console industry. Journal of Marketing 75(6), 39-54.

19. McAfee, P., Mialon, H.M., and Williams, M.A. (2004). What is a barrier to entry? The American Economic Review 94(2), 461-465.

20. Rochet, J.C., and Tirole, J. (2003) Platform competition in two-sided markets. Journal of the European Economic Association, 1(4), 990-1029

21. Rochet, J.C., and Tirole, J. (2006). Two-sided markets: A progress report. The RAND Journal of Economics 37(3), 645-667.

22. Sun, M. and Tse, E. (2007). When does the winner take all in two-sided markets?. Review of Network Economics 6(1), 16-40.

23. Suominen, A., Hyrynsalmi, S., and Seppänen, M. (2016) Ecosystems Here, There and Everywhere - A Barometrical Analysis of the Roots of 'Software Ecosystems'. In: Maglyas, A., Lamprecht, A.-L. (eds) Software Business: 7th International Conference, ICSOB 2016, Ljubljana, Slovenia, June 13-14, 2016, Proceedings, Springer International Publishing, p. $32-46$. 
24. Teixeira, J., and Hyrynsalmi, S. (2017) How do Software Ecosystems Co-Evolve? A view from OpenStack and beyond. In: Ojala, A. (ed) Software Business: 8th International Conference, ICSOB 2017, Springer International Publishing, p. 1-15. 